\title{
Physical Education Teachers' Perspectives in a Changing World: From Future Studies to New Physical Culture
}

\author{
Oksana Voitovska \\ $\mathrm{PhD}$, Associate Professor, National Pedagogical Dragomanov University (Kyiv, Ukraine) \\ E-mail: ovoitovskaya@ukr.net \\ ORCID: 0000-0002-1814-5895
}

Svitlana Tolochko

$\mathrm{PhD}$, Associate Professor, National Pedagogical Dragomanov University (Kyiv, Ukraine)

E-mail: svitlana-tsv@ukr.net

ORCID: 0000-0002-9262-2311

The article deals with the physical education teachers' perspectives in a changing world. Technologies of transhumanism are aimed at expanding human biological capabilities and creating a posthuman, in which natural organs and organ systems are planned to replace with artificial transplants. Thus, these technologies make it necessary to reconsider the established views on physical culture and the goals of teaching physical education.

The author uses the comparative analysis to compare the foundations of futures studies, using examples from the academic journal Future Human Image, specializing in futures studies, as well as the physical education teachers' perspectives which are revealed in the Journal of Teaching in Physical Education (JTPE). This journal focuses on the stimulating discussion, study, and critique of teaching, teacher education, and curriculum in fields related to physical activity in schools, communities, higher education, and sport. As a result of the analysis, the author concludes that in spite of ideas of transhumanism and other futures studies, physical culture and physical education, which move into the mass consciousness actively, retain topicality. The recommendations are taken into account in futures studies and studies in the field of physical culture.

Keywords: futures studies, Future Human Image, physical education, physical education teacher, physical culture, Journal of Teaching in Physical Education, transhumanism.

Received 23 April 2017; accepted 12 July 2017

Philosophy and Cosmology, Volume 20, 2018: 139-145

DOI: $10.29202 /$ phil-cosm/20/13

(C) Voitovska, Oksana, 2018

(C) Tolochko, Svitlana, 2018 


\section{Introduction}

At the end of $20^{\text {th }}$ - the beginning of $21^{\text {st }}$ centuries widespread was an international and intellectual movement, called transhumanism. The word "transhumanism" has been firstly used by Julian Huxley in 1927. He put the following meaning into it: "The human species can, if it wishes, transcend itself, not just sporadically, an individual, in one way, in the whole way, as in humanity. We need a name for this new belief. Perhaps transhumanism will serve: man remaining man, but transcending himself, by realizing new possibilities for and for his human nature" [Bostrom, 2005]. Using interdisciplinary research in the fields of philosophy, biology, genetic engineering, etc., transhumanism declares "... envision the possibility of broadening human potential by accident, overcoming aging, cognitive shortcomings, involuntary suffering, and our confinement to planet Earth" [Bostrom, 2005].

Representatives of transhumanism believe that revolutionary discoveries in nanotechnology, nanomedicine, biotechnology, genetic engineering, cloning, transgenesis, and bionics, as well as their practical use, will lead to the emergence of posthuman (a Posthuman) and the philosophy of posthumanism. In studies on the extension of human life, which are associated mainly with the replacement of natural organs with artificial ones, billions of dollars are invested annually. Currently, transhumanism is officially represented by the international public organization "Humanity +" (Humanity + is an international nonprofit membership organization) (http://humanityplus.org/), that advocates the ethical use of technology to expand human capacities.

Methodological clarity in the interpretation of the principles of posthumanism and transhumanism in our study allows us to make the following thesis: "Transhumanism focuses on technologies that can enhance normal human functions rather than create new ones. By contrast, posthumanism moves beyond transhumanism and adopts 'science fiction' ideas and concepts, according to which the 'posthuman' will be the biotechnologically mutated non-human, a creature which will remain biologically encased at the same time origin" [Karamanou et al., 2017: 677].

The author of the article sets a goal to review contemporary publications in order to conceptualize the problem of representation in modern educational strategies of the image of the future person, and also to diagnose the degree of correlation of approaches to understanding modern physical culture with the principles of posthumanism (transhumanism). This research perspective will make it possible to impart philosophical content to the processes of modernization of education, including pedagogical content, at the same time when complex, multidimensional transformations take place in it [Andrushchenko \& Seveliev, 2016; Bazaluk et al., 2017; Dawidow, 2016; Svyrydenko, 2016a; Svyrydenko, 2016b].

\section{Foundations of Futures Studies}

The researches of transhumanism, posthumanism, etc. are carried out within the boundaries of futures studies. In order to put together an objective idea of futures studies, we turned to one of the specialized journals in this field - to the academic journal Future Human Image (http://www.fhijournal.org). The journal Future Human Image is a project of the International Society of Philosophy and Cosmology (http://en.bazaluk.org/). The main aim, which is pursued by the editorial board, consists of the future human image. The journal publishes studies that are aimed at studying new technologies in the field of human development of the future, as well as embodiment ideas of transhumanism, the philosophy of space, and so on in everyday life. 
Among the publications in the journal Future Human Image for the past three years, we note the work of the following authors. The article of Arkady Ursul and Tatiana Ursul is devoted to the close connection between the features of the development of modern education and the process of globalization. The authors write: "Educational process, which is still focused on the formation of the individual, to some extent, on more extensive, supraindividual sociosystems, being included in the integrative information structures of the mind and in perspective creation of a noospheric global space socio-ecological system. There is expected unification of learning and education as important subsystems of the future noospheric intelligence into one holistic system" [Ursul \& Ursul, 2017: 152]. This article demonstrates the potential for correlating the fundamental foundations of the educational process with the logic of socio-cultural transformations taking place in the modern global world.

Oleg Bazaluk deepens and gives practical meaning to the research of Arkady Ursul and Tatiana Ursul. His research is devoted to a new understanding of the philosophy of education. Bazaluk considers education, primarily as a consequence of modern research in the field of neuroscience and cognitive psychology. Building educational technologies based on neurophilosophy and cognitive psychology, opens up new, more effective ways of influencing the human brain; more complete disclosure of its capabilities in ontogeny and cultural history [Bazaluk, 2015; Bazaluk, 2016].

A special place in the works is occupied by the problems of possible transformations of human corporeity in connection with the rapid development of modern technologies, as well as the challenges that the education system may face, the subject of which will be the posthuman of the new millennium. Denys Svyrydenko's research is devoted to a mobilities paradigm. Svyrydenko is considering the rapid spread of discoveries in the field of futures studies in contemporary society, including through academic mobility [Svyrydenko, 2016a]. According to the approaches proposed by the author, students of higher educational institutions, having access to various educational traditions, achievements of scientific schools and cultural traditions, readily and easily perceive the ideas of transhumanism, and using social networks and interactive communication, transfer them on a global scale. Indeed, the mobile world, to ensure its mobile status, transforms everyday human practices, giving them a dynamic character. The sphere of education most vividly demonstrates the declared tendency: "At the 21st century life success depends on the people's ability to build the life strategies (as well as educational ones) taking into account the mobility tendencies at the modern society" [Svyrydenko, 2016a: 103].

The special emphasis deserves the research by Sergey Krichevsky on cosmic humanity. According to Krichevsky, cosmic humanity is (essence and 4 stages of evolution): 1. Humanity living on Earth, sensing, knowing, understanding its cosmic origin, relationship with the cosmos and cosmic destiny. 2. Humanity living on Earth, leading aerospace activity for the purposes of exploration and use of aerospace space (Heaven, Space) for survival and development. 3. Humanity living on Earth and outside the Earth - in the solar system, preserving the Earth and mastering the Cosmos for survival and development. 4. Humanity, settled and living in the Cosmos [Krichevsky, 2017: 53]. For our study, the conclusion to which Krichevsky came is important: "Cosmic humanity has an evolutionary purpose for actively managing evolution: change man, humanity and the universe" [Krichevsky, 2017: 54]. This study offers an updated anthropological project for the conceptualization of a series of changes that are coming to humanity as a continuously evolving entity.

Roman Oleksenko and Lidiia Fedorova are exploring the project "Asgardia" Nation State in space that has been sensational in the last few years. They see the future human image as 
Homo Economicus, whose main characteristics are both the cause and the consequence of the development of the "Asgardia" Nation State in space [Oleksenko \& Fedorova, 2017]. Despite being distanced from the problem of immediate changes in human corporeality, this paper offers a philosophical revision of the people's everyday practices of the future in the context of the space development technologies and successes in mastering other planets.

Finally, we note a study by Javier Collado-Ruano, which reveals the possibilities of biomimicry, as a new approach to innovation that seeks sustainable solutions to human challenges by emulating nature's time-tested patterns and strategies [Collado-Ruano, 2015].

In general, the analysis of futures studies based on the articles of the latest issues of the academic journal Future Human Image showed that the authors of futures studies do not directly link the future of mankind to physical culture, don't give the physical education the proper attention. At the same time, speaking about education for future generations, it is not logical to exclude the problems of the new physical culture from the research contexts. This fact challenges the need to search for updated educational strategies for the training of physical education teachers, bringing these strategies in line with the demands of the new society and an updated anthropological project for all of humanity.

\section{Physical Culture and Physical Education in Future Perspectives}

Physical education teachers' perspectives are examined not only in numerous articles and in books - they are dedicated to a separate journal with its own history. This is the Journal of Teaching in Physical Education (JTPE) (http://journals.humankinetics.com/journal/ jtpe), which is published by the international organizations of Human Kinetics (http://www. humankinetics.com).

Human Kinetics states that one's mission is to produce innovative, informative products in all areas of physical activity that help people worldwide lead healthier, more active lives. Human Kinetics is committed to providing quality informational and educational products in the physical activity and health fields that meet the needs of our diverse customers. Within the physical activity field, recreational and organized sports are a major focus. Website of the Journal says that purpose of the Journal of Teaching in Physical Education is to communicate national and international research and stimulate discussion, study, and critique of teaching, teacher education, and curriculum as these fields relate to physical activity in schools, communities, higher education, and sport.

Most of the articles in the Journal of Teaching in Physical Education are devoted to practice. They not only promote physical culture, but also through physical education help to introduce it into the consciousness and way of the younger generations' life. From research for the past three years, we note the following. In the article Athanasios Papaioannou, based on recent trends in positive psychology, on ancient Greek sport literature and particularly on Aristotle's philosophy, the holistic, harmonious and internal motivational components of excellence and their implications for students' motivation for physical activity, health and well-being are presented.

The author insists on the need to focus on the promotion of Olympic ideals, such as excellence, friendship, and respect [Papaioannou, 2017]. Despite the renewal of ideas about a person in the context of using the potential of scientific and technological progress in everyday human practices, the author defends, the need to broadcast the Olympic ideals in physical culture at all times.

The particular interest is the article by Thomas McKenzie, James F. Sallis, Paul Rosengard, and Kymm Ballard, creators of another important project in the field of physical culture, 
SPARK: Sports, Play, and Active Recreation for Kids (http://www.sparkpe.org/). SPARK in its current form, is a brand that represents a collection of exemplary, research-based, physical education and physical activity programs that emphasize a highly active curriculum, on-site staff development, and follow-up support. Given its complexity (e.g., multiple school levels, inclusion of both physical education and self-management curricula), SPARK features both diverse instructional and diverse curricular models. Procedures used in SPARK may serve as models for others interested in researching and disseminating evidence-based physical education and physical activity programs [McKenzie et al., 2016]. The article offers a new image of the subject of physical culture in the educational process, as well as strategies for harmonizing the new ideology of physical activity with the educational process. At the center of these changes is the image of a new teacher of physical culture, a bearer of a new level of knowledge and ideological orientations, resonating with changes in modern social order.

In the article Jesse L. Rhoades, Amelia Mays Woods, David Newman Daum, Douglas Ellison, and Thomas N. Trendowski presents an examination of 30 years of Journal of Teaching in Physical Education (JTPE) research. The purpose of this study was to provide a retrospective view of JTPE and its contribution to the field of physical education. Thematic analysis revealed that the topical content of the journal has remained consistent over the course of its operation [Rhoades et al., 2016].

In general, the articles analysis in The Journal of Teaching in Physical Education (JTPE) showed that over the past three years, studies in the field of physical culture and physical education have not lost their relevance. New methods of research are being developed and introduced, models based on practice in physical education, which allow to educate modern generations on the same ideals as the generations of Antiquity. At the same time, the system of teacher training rationally justified the possibility of an effective combination of traditions and innovations in education, the ideological approaches of the present and the ideals of Antiquity are harmonized. At the same time, physical culture appears as an instrument of sustainable development of human civilization in the projects of post-humanism and transhumanism.

\section{Conclusions}

The comparative analysis of futures studies and studies in the field of physical culture, on the example of two specialized journals Future Human Image and Teaching in Physical Education, allowed us to come to the following conclusions:

1. The ideas of transhumanism and the creation of a posthuman, like the future human image, are not based on physical culture and most do not. Rather, on the contrary, they are trying to offer a culture that at first sight excludes physical education. Nanotechnology, nanomedicine, biotechnology, genetic engineering, cloning, etc. are directed on expansion of biological possibilities of an organism due to artificial intervention in natural processes. However, with a more in-depth study of futures studies, we arrive at a completely opposite result. In our opinion, only physical culture and physical education are able to ensure the effectiveness of transhumanism and the life of a posthuman. No artificial interference in biological processes is able to cancel Olympic ideals, such as excellence, friendship, and respect. On the contrary, for the future human image, these ideals are of paramount importance and occupy a key role in the culture of posthumanism.

2. Physical culture and physical education aimed at the full development of biological capabilities of the body. No matter how artificial the brain surrounds itself and its manifestations, the effectiveness of its functioning and manifestations depends entirely on 
the physiology of the organism. The health of the organism is a pledge of the full activity of the brain and the effectiveness of its manifestations.

3. In David Kirk's study, which has become classic, the revival of the topicality of the physical culture is described as one dimension of the corporeal discourse, concerned with the meaning-making in and around the body, centered on sport, physical recreation and exercise as three institutionalized, codified forms of physical activity [Kirk, 1999]. Those Kirk suggests treating physical culture as a discourse about the body.

4. In the culture of the future, the role of the physical education teacher by no means becomes secondary. Quite the contrary, the struggle to increase life expectancy and its quality significantly expands the physical education teachers' perspectives in a changing world. As follows from the same studies of neuroscience, the full development of the structure and functions of the human brain directly depends on the usefulness of the development of the body's biological functions. A fully functioning brain develops only in a harmoniously functioning organism, for which the physical education teacher is responsible. Physical culture and physical education become the guarantor of the introduction and full work of nanomedicine products, genetic engineering, cloning, etc., because they create favorable and necessary soil for this. It is the physical education teacher that determines the methods and ways of working with the younger generations in the culture of transhumanism.

This issue was considered by the author in his works, for example, in the article "Voices of Professional Development of Physical Training Teachers in the Conditions of Postgraduate Education" [Voitovska, 2016]. The Journal of Teaching in Physical Education (JTPE) presents numerous studies that prove the advanced role of physical education teachers in preparing schoolchildren and students for a new way of life and for new ideas that their bodies need to adapt.

5. Studies of the future largely ignore physical culture and are based on completely different postulates. From our point of view, this is an erroneous and deadlock solution, which will have to resort to physical culture and physical education. Our analysis shows that, starting from the culture of Antiquity, and up to the culture of Modernity, physical culture and physical education have played and continue to play an important role in human development. This question is identical to the level of the nation's health and the future of civilization, since only a healthy organism is capable of reproducing healthy offspring and guarantee the formation and development of a healthy psyche.

\section{References}

Andruschenko, Viktor, and Volodymyr Saveliev. Commentary Pedagogical Constitution of Europe. Interdisciplinary Studies of Complex Systems, No. 8, 2016: 30-32.

Bazaluk, Oleg. Postmodernism: Philosophy of Education. Future Human Image, 2 (5), 2015: 9-22.

Bazaluk, Oleg. The Philosophy of Cosmos: the Place of Human at the Scale of Earth and Cosmos. Philosophy and Cosmology, 16, 2016: 28-42.

Bazaluk, Oleg, Denys Svyrydenko, and Serhii Terepyshchyi. Structural-functional models of integration and reintegration of Ukrainian educational landscape. Naukovyi Visnyk Natsionalnoho Hirnychoho Universytetu, 5, 2017: 163-168.

Bostrom, Nick. A History of Transhumanist Thought. Journal of Evolution and Technology, Vol. 14 (1), 2005: 1-25. http://www.nickbostrom.com/papers/history.pdf

Collado-Ruano, Javier. Biomimicry: a Necessary Eco-Ethical Dimension for a Future Human Sustainability. Future Human Image, 2 (5), 2015: 22-57. 
Dawidow, Pavel. Continuing Education as a New Paradigm: the Synergy Analysis. Studia Warmińskie, 53, 2016: 67-75.

Karamanou, Marianna, Theodore G. Papaioannou, Dimitrios Soulis, and Dimitrios Tousoulis. Engineering 'Posthumans': To Be or Not to Be? Trends in Biotechnology, 35(8), 2017: 677-679.

Kirk, David. Physical Culture, Physical Education and Relational Analysis. Sport, Education and Society, Volume 4, 1999: 63-73.

Krichevsky, Sergey. Cosmic Humanity: Utopia, Realities, Prospects. Future Human Image, 7, 2017: 50-70.

McKenzie, Thomas, James F. Sallis, Paul Rosengard, and Kymm Ballard. The SPARK Programs: A Public Health Model of Physical Education Research and Dissemination. Journal of Teaching in Physical Education, 35, 2016: 381-389.

Oleksenko, Roman and Lidiia Fedorova. Homo Economicus as the Basis of "Asgardia" Nation State in Space: Perspective of Educational Technologies. Future Human Image, 7, 2017: 113-119.

Papaioannou, Athanasios G. Teaching a Holistic, Harmonious and Internal Motivational Concept of Excellence to Promote Olympic Ideals, Health and Well-Being for All. Journal of Teaching in Physical Education, 36, 2017: 353-368.

Rhoades, Jesse L., Amelia Mays Woods, David Newman Daum, Douglas Ellison, and Thomas N. Trendowski. JTPE: A 30-Year Retrospective of Published Research. Journal of Teaching in Physical Education, 35, 2016: 4-15.

Svyrydenko, Denys. Mobility Turn in Contemporary Society as an Educational Challenge. Future Human Image, 3 (6), 2016: 102-108.

Svyrydenko, Denys. Plagiarism challenges at Ukrainian science and education. Studia Warmińskie, 53, 2016: 67-75.

Ursul, Arkady, and Tatiana Ursul. Education and Globalistics. Future Human Image, 7, 2017: 136-153.

Voitovska, Oksana. Features of Professional Development of Physical Training Teachers in the Conditions of Postgraduate Education. Scientific Notes of Ternopil Volodymyr Hnatiuk National Pedagogical University, 3, 2016: 81-87. 